\title{
Determination of Model Kinetics for Forced Unsteady State Operation of Catalytic $\mathrm{CH}_{4}$ Oxidation
}

\author{
Mohammad Effendy ${ }^{1}$ and Endarto Y. Wardhono ${ }^{2}$ \\ 1 Surabaya State University, in Surabaya, Indonesia \\ 2 University of Sultan Ageng Tirtayasa, Indonesia
}

\begin{abstract}
The catalytic oxidation of methane for abating the emission vented from coal mine or natural gas transportation has been known as most reliable method. A reverse flow reactor operation has been widely used to oxidize this methane emission due to its capability for autothermal operation and heat production. The design of the reverse flow reactor requires a proper kinetic rate expression, which should be developed based on the operating condition. The kinetic rate obtained in the steady state condition cannot be applied for designing the reactor operated under unsteady state condition. Therefore, new approach to develop the dynamic kinetic rate expression becomes indispensable, particularly for periodic operation such as reverse flow reactor. This paper presents a novel method to develop the kinetic rate expression applied for unsteady state operation. The model reaction of the catalytic methane oxidation over Pt/ - $\mathrm{Al}_{2} \mathrm{O}_{3}$ catalyst was used with kinetic parameter determined from laboratory experiments. The reactor used was a fixed bed, once-through operation, with a composition modulation in the feed gas. The switching time was set at $3 \mathrm{~min}$ by varying the feed concentration, feed flow rate, and reaction temperature. The concentrations of methane in the feed and product were measured and analysed using gas chromatography. The steady state condition for obtaining the kinetic rate expression was taken as a base case and as a way to judge its appropriateness to be applied for dynamic system. A Langmuir-Hinshelwood reaction rate model was developed. The time period during one cycle was divided into some segments, depending on the ratio of $\mathrm{CH}_{4} / \mathrm{O}_{2}$. The experimental result shows that there were kinetic regimes occur during one cycle: kinetic regime controlled by intrinsic surface reaction and kinetic regime controlled by external diffusion. The kinetic rate obtained in the steady state operation was not appropriate when applied for unsteady state operation. On the other hand, the kinetic rate expression obtained in the unsteady state operation fitted quite well. It was proven that in one cycle period the kinetic rate would always shift according to the ratio of $\mathrm{CH}_{4} / \mathrm{O}_{2}$.
\end{abstract}

\section{Introduction}

The increase of methane emission rate and high global warming potential, if not treated, can induce a negative impact on the environment. The catalytic treatment of methane emissions is one of the most reliable alternatives to be applied. However, since the concentration of emitted methane is low, the flow rate and concentration changes over time, and the temperature is ambient, the conventional treatment using oncethrough fixed bed reactor operating under steady state conditions is less appropriate. For the methane content of $0.5 \%-\mathrm{v}$, the adiabatic temperature rise is approximately $115^{\circ} \mathrm{C}$. As a result, extra external energy is required to increase the temperature of the feed gas. Reverse flow reactor is a new solution that has been well proven to abate the exhaust gas emission auto thermally with characteristics as aforementioned. Reverse flow reactor may be defined as a fixed bed reactor in which the flow direction is altered periodically. Moreover, the reverse flow reactor could also improve the average methane conversion compared to the one obtained from steadystate operation.

Increased conversion of methane may be induced by changes of the reaction rate of methane over catalyst surface due to dynamic system operated at proper time scale. Therefore, there are two important aspects to be considered, (1) reactor design, (2) operation method. In the dynamic reactor, the mechanism and the ratecontrolling step are always changing at each operating cycle. This change indicates that the reactor which is designed based on the steady state will give a different result compared with reactor which is designed based on the dynamic state. To the best of our knowledge, operating the dynamic reactor is usually designed on the basis of steady state condition due to no approach that has been developed, implementing the dynamic system in designing a reactor.

Development of dynamic operation is divided into two important aspects studied by many researchers, aspect of the design and method of operation. On aspects of the operation method, the goal is to get the proper 
operating procedures in order to obtain a better objective function of the steady state [1], [2]. However, on the research aspects of operating procedures was not studied.

In the designing aspect, to the lean methane oxidation on dynamic conditions, research led to the determination of catalyst for improved performance of the dynamic reactor [3]-[5]. Research related with the reaction rate in dynamic conditions is still limited to the suitability of the use of models of the reaction mechanism. Lopez et al. (2001) studied the effect of kinetic model (power law and LH) for methane combustion reaction against auto thermal operation on the catalytic reactor [6].

It is shown in different steady-state conditions, research on the reaction rate has been done, such as: determining step reaction mechanism for methane oxidation using Pt catalyst [7] developed a kinetic model for the methane oxidation using a catalyst $\mathrm{Pd} / \mathrm{Al}_{2} \mathrm{O}_{3}$ in dry and wet conditions [8], studied and proposed a Langmuir-Hinshelwood reaction mechanism for the methane oxidation [9], study the reaction mechanism of the catalytic oxidation of a mixture of methane - water vapor using a fixed bed reactor [10], and study the reaction mechanism of the catalytic oxidation of a mixture of methane - hydrogen using a fixed bed reactor [11].

Based on previous research overview (state of the art), the reaction mechanism of methane oxidation on the dynamic conditions in one cycle has not been fully explained. Reaction mechanisms and rate controlling step reaction that occurs during dynamic conditions become a fundamental requirement for the design of the reactor is operated under dynamic conditions. Therefore, the methods to get the reaction rate on dynamic conditions need to be developed further.

\section{Materials and Methods}

The target research is to get a reaction mechanism that occurs in a dynamic period. The technique used by the approach steady state, i.e. the segment the dynamic condition in a steady state conditions. Study includes;

1) to obtain the equation lean methane oxidation kinetics under conditions of excess oxygen using a catalyst $\mathrm{Pt} / \gamma-\mathrm{Al}_{2} \mathrm{O}_{3}$

2) to test the suitability of kinetic equations for a single cycle of dynamic conditions,

3 ) to identify the effect of disturbance (feed composition modulation) on the response of the reactor (conversion of methane) and define the points disturbance which allegedly has a different reaction mechanism,

4) to establish equality for lean methane oxidation kinetics under the same conditions with the results of disturbance points identified in step 3 ,

$5)$ to develop a model of lean methane oxidation kinetics in dynamic conditions and validate the dynamic model of kinetic equations is obtained.

Kinetic equations for lean methane oxidation in excess oxygen conditions obtained tested for compliance to dynamic conditions. Conformance testing is done by modeling and simulation. The model used is the pseodohomogeneous continuum model 1D with the completion of the model using FlexPDE software version 6. These results provide direction, whether further steps need to be done or not.

Identify the effects of disturbance on the response of the reactor is expressed in feed concentration ratio $\mathrm{CH}_{4} / \mathrm{O}_{2}$ toward the methane conversion. Identification is done by analyzing and setting points of the feed concentration ratio $\mathrm{CH}_{4} / \mathrm{O}_{2}$ who allegedly had a different reaction mechanism.

Determination of reaction mechanisms and kinetics parameters on the conditions of the points that have been assigned disturbance conducted at steady state condition. Model of the reaction mechanism used model-based Langmuir-Hinshelwood (LH). The method used is the technique of fitting parameters on LH models with experimental data is carried out with the help of the software matlab.

Reaction mechanism in dynamic conditions is obtained by identifying changes in the mechanisms and rate controlling step reaction, did segmentation in the range of change reaction mechanisms, and validate the model of mechanism reaction in one cycle of dynamic operations.

\section{Results and Discussions}

\subsection{Catalytic oxidation of lean methane in excess oxygen conditions}

Model of the reaction mechanism used is the model of Langmuir-Hinshelwood (LH). The experiments were performed at steady state with a variable range of the experiment are as follows: minimum feed linear velocity of $7.5 \mathrm{e}^{-4} \mathrm{~m} / \mathrm{sec}$, the catalyst mass 0.5 grams with a diameter of $2 \mathrm{~mm}$ catalyst, and reaction temperature $500^{\circ} \mathrm{C}, 520^{\circ} \mathrm{C}$ and $540^{\circ} \mathrm{C}$. Range is based on the results of experiments testing the effect of external and internal mass transfer.

There are three models were tested based on the assumption LH reaction mechanism, which is derived based on the assumption of the model LH1 controlling phase adsorption of methane, LH2 models based on oxygen adsorption stage controller, and LH3 models based on surface reaction between methane with one atom of oxygen adsorbed. Results obtained by using the technique of fitting parameters LH models with experimental data is carried out with the help of matlab software are shown in Table 1.

The kinetics parameter of lean methane oxidation under conditions of excess oxygen has been obtained (see Table 1) tested for compliance to one cycle of dynamic conditions in the next step.

\subsection{Suitability test for one kinetics equation on dynamic conditions}

Disturbance created to make dynamic condition is obtained by modulating the composition of the feed. This 
resulted in the concentration of the feed gas changes each time as shown in Figure 1.

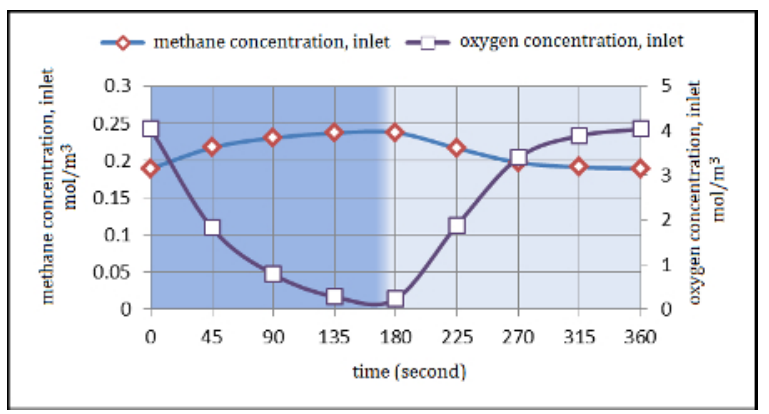

Figure 1. Behaviour of the oxygen concentration and the concentration of methane in the input due to interference open / close the flow of oxygen at the periodic switching time of 180 seconds. Initial conditions: a linear flow rate of $\mathrm{CH}_{4} 0.00030$ $\mathrm{m} / \mathrm{sec}$ at a concentration of $1 \%$ methane in air-mole.

The model used to test the suitability of kinetic parameters in dynamic operating one-cycle is pseudohomogeneous 1D continuum model. Pseudohomogeneous 1D continuum model equation and its boundary conditions are shown by Equation 1-3.

$\varepsilon_{\text {bed }} \frac{\partial C_{\mathrm{CH} 4}}{\partial t}=D_{\text {eff }} \frac{\partial^{2} C_{C H 4}}{\partial z^{2}}-u \frac{\partial C_{C H 4}}{\partial z}-\eta \rho_{\text {kat }} r_{C H 4}$

$\varepsilon_{b e d} \frac{\partial C_{D 2}}{\partial t}=D_{e f f} \frac{\partial^{2} C_{D 2}}{\partial z^{2}}-u \frac{\partial C_{D 2}}{\partial z}-\eta \rho_{\text {hat }} r_{02}$

with boundary conditions:

$\mathrm{z}=0$, at $\mathrm{t}=0-180$ seconds,

$C_{02}^{0}=a \cdot t^{4}+b_{0} t^{3}+c_{0} t^{2}+d \cdot t+e$

$C_{\mathrm{CH} 4}^{0}=f \cdot t^{4}+g \cdot t^{a}+h \cdot t^{2}+i \cdot t+j$

$u^{0}=k \cdot t^{4}+l \cdot t^{3}+m \cdot t^{2}+n \cdot t+t$

at $\mathrm{t}=180-360$ seconds,

$C_{02}^{0}=a_{1} \cdot t^{4}+b_{1} \times t^{3}+c_{1} \cdot t^{2}+d_{1} \cdot t+e_{1}$

$C_{\mathrm{CH} 4}^{0}=f_{1} \cdot t^{4}+g_{1} \cdot t^{a}+h_{1} \cdot t^{2}+i_{1} \cdot t+j$

$u^{0}=k_{1} \cdot t^{4}+l_{1} \cdot t^{3}+m_{1}, t^{2}+n_{1} \cdot t+t$

If $\mathrm{z}=\mathrm{L}, \frac{\partial C \mathrm{H}_{4}}{\partial z}=\frac{\partial O_{2}}{\partial z}=0$

where the polynomial equation for the change in concentration and flow rate in the boundary condition refers to a pattern of behavior shown in Figure 1 and the rate equation for the reaction rate in Equation 1 and 2 refer to Table 1. Simulation results are shown in Figure 2.

The controlling stage is methane adsorption (A), the controlling stage is oxygen adsorption (B) and the controlling stage is reaction at the surface $(\mathrm{C})$. Initial conditions: a linear flow rate of methane $0.00045 \mathrm{~m} / \mathrm{sec}$ at a concentration of $1 \%$ methane in air-v.

of feed gas. This is shown by the comparison of experimental data and simulation on dynamic conditions, at the
From Figure 2 can be expressed, obtained methane conversion in dynamic conditions is not sufficiently influenced by changes in the concentration and flow rate
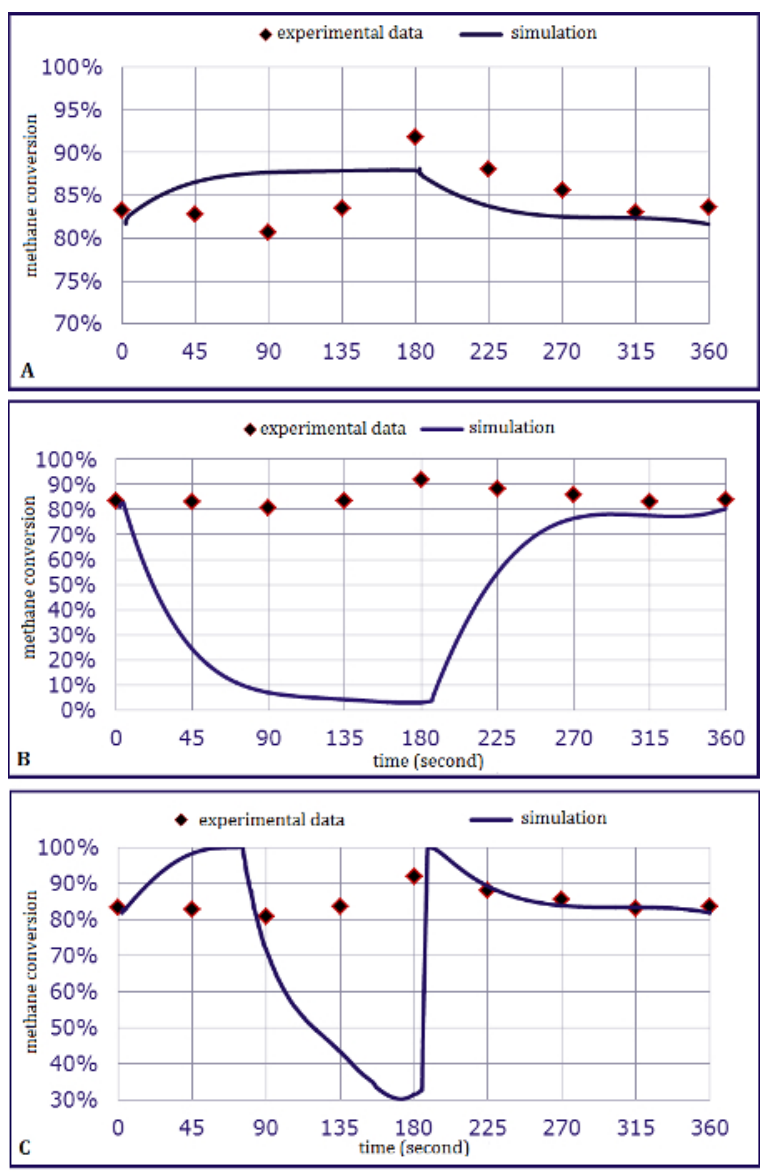

Figure 2. Comparison of methane conversion on dynamic conditions between the experimental results with simulations

condition of small $\mathrm{CH}_{4} / \mathrm{O}_{2}$ feed concentration ratio, ie the excess oxygen conditions, the reaction rate is controlled by surface reaction between $\mathrm{CH}_{4}$ with 1 atom $\mathrm{O}_{2}$. However, at the feed concentration ratio greater $\mathrm{CH}_{4} / \mathrm{O}_{2}$, ie the lack of oxygen conditions, the conversion of methane simulation results with experimental data is different on all three kinetic parameters were tested. So that the alleged change in the reaction mechanism at dynamic conditions will be identified at a later stage. 
Table 1. Methane oxidation reaction kinetics parameters for three models

\begin{tabular}{|c|c|c|c|}
\hline controlling phase & reaction rate equation & parameter & error \\
\hline adsorption of $\mathrm{CH}_{4}$ & $\frac{k_{1} C_{C H 4}}{1+\sqrt{K_{2} C_{O 2}}}$ & $\begin{array}{l}k_{1}=1488 \exp \left(\frac{-82245.41}{R T}\right) \\
K_{2}=\exp \left(-\frac{8373.61}{R}+\frac{44640.9}{R T}\right)\end{array}$ & $3.7 \%$ \\
\hline adsorption of $\mathrm{O}_{2}$ & $\frac{k_{2} C_{O 2}}{\left(1+\sqrt{K_{1} C_{\mathrm{CH} 4}}\right)^{2}}$ & $\begin{array}{l}k_{2}=1.26 \exp \left(\frac{-48201.58}{R T}\right) \\
K_{2}=\exp \left(-\frac{231.94}{R}+\frac{3048.74}{R T}\right)\end{array}$ & $7.0 \%$ \\
\hline $\begin{array}{l}\text { Surface reaction between } 1 \\
\text { atom of } \mathrm{O}_{2} \text { with } 1 \text { atom of } \mathrm{CH}_{4}\end{array}$ & $\frac{k_{a} K_{1} C_{C H 4} \sqrt{K_{2} C_{O 2}}}{\left(1+K_{1} C_{C H 4}+\sqrt{K_{2} C_{O 2}}\right)^{2}}$ & $\begin{array}{l}k_{2}=112726 \exp \left(\frac{-9204.71}{R T}\right) \\
K_{1}=\exp \left(-\frac{2.30}{R}+\frac{39192.47}{R T}\right) \\
K_{2}=\exp \left(-\frac{159.22}{R}+\frac{235774.78}{R T}\right)\end{array}$ & $3.6 \%$ \\
\hline
\end{tabular}

Table 2. Kinetics parameters in three conditions $\mathrm{CH}_{4} / \mathrm{O}_{2}$ feed gas concentration ratio $(\varphi)$

\begin{tabular}{|c|c|c|c|c|}
\hline$\varphi$ & reaction mechanism & $\begin{array}{c}\text { controlling } \\
\text { phase }\end{array}$ & reaction rate equation & Parameter \\
\hline 0.05 & $\begin{array}{l}\text { Total oxidation reaction } \\
\qquad \mathrm{r}_{\mathrm{CH} 4-\mathrm{t}} \\
\mathrm{CH}_{4}+\mathrm{O}_{2} \rightarrow \mathrm{CO}_{2}+\mathrm{H}_{2} \mathrm{O}\end{array}$ & $\begin{array}{l}\text { Surface } \\
\text { reaction } \\
\text { between } 1 \\
\text { atom of } \mathrm{O}_{2} \\
\text { with } 1 \text { atom of } \\
\mathrm{CH}_{4}\end{array}$ & $\frac{k_{a} K_{1} C_{C H} \sqrt{K_{2} C_{O 2}}}{\left(1+K_{1} C_{C H 4}+\sqrt{K_{2} C_{O 2}}\right)^{2}}$ & $\begin{array}{l}k_{2}=369743 \exp \left(\frac{-9204.71}{R T}\right) \\
K_{1}=\exp \left(-\frac{2.30}{R}+\frac{39192.47}{R T}\right) \\
K_{2}=\exp \left(-\frac{159.22}{R}+\frac{235774.78}{R T}\right)\end{array}$ \\
\hline 1 & $\begin{array}{l}\text { Partial oxidation } \\
\text { reaction } \\
\quad \mathrm{r}_{\mathrm{CH} 4-\mathrm{pl}} \\
\mathrm{CH}_{4}+\mathrm{O}_{2} \rightarrow \mathrm{CO}_{2}+2 \mathrm{H}_{2}\end{array}$ & $\begin{array}{l}\text { Surface } \\
\text { reaction } \\
\text { between } 1 \\
\text { atom of } \mathrm{O}_{2} \\
\text { with } 1 \text { atom of } \\
\mathrm{CH}_{4}\end{array}$ & $\frac{k_{a} K_{1} C_{\mathrm{CH} 4} \sqrt{K_{2} C_{\mathrm{O} 2}}}{\left(1+K_{1} C_{\mathrm{CH} 4}+\sqrt{K_{2} C_{\mathrm{O} 2}}\right)^{2}}$ & $\begin{array}{l}k_{21}=4850 \exp \left(\frac{-9204.71}{R T}\right) \\
K_{1}=\exp \left(-\frac{21.79}{R}+\frac{53526.41}{R T}\right) \\
K_{2}=\exp \left(-\frac{31.86}{R}+\frac{91828.98}{R T}\right)\end{array}$ \\
\hline 2.5 & $\begin{array}{l}\text { Decomposition reaction } \\
\text { of methane, } \mathrm{r}_{\mathrm{CH}} \text {-p } \\
\mathrm{CH}_{4}+\mathrm{O}_{2} \rightarrow \mathrm{C}+2 \mathrm{H}_{2} \mathrm{O}\end{array}$ & $\begin{array}{l}\text { External } \\
\text { diffusion }\end{array}$ & $r=A_{0} \exp \left(\frac{-E_{a}}{R T}\right) C_{C H 4}$ & $\begin{array}{l}A_{0}=-0.0821 \varphi^{2}+3172 \varphi-0.2112 \\
\text { For } 1 \leq \varphi \leq 1.92 \\
A_{0}=0.0064 \ln (\varphi)+0.0918 \\
\text { For } 1.92 \leq \varphi \leq 3.8 \mathrm{E}, E_{a} \equiv 6300\end{array}$ \\
\hline
\end{tabular}

\subsection{Identify the influence of disturbances (feed composition modulation) on the response of the reactor (methane conversion)}

The feed concentration is changing due to the feed composition modulation expressed in concentration ratio feed $\mathrm{CH}_{4} / \mathrm{O}_{2}$. The relationship concentration ratio feed $\mathrm{CH}_{4} / \mathrm{O}_{2}$ with methane conversion is shown in Figure 3.

The changes in feed concentration ratio $\mathrm{CH}_{4} / \mathrm{O}_{2}(\varphi)$ possess different trend pattern with methane conversion.
This difference is thought to be caused by changes in the reaction mechanism. In order to identify the reaction mechanisms involved in the dynamic operating cycle, the three point determined $\mathrm{CH}_{4} / \mathrm{O}_{2}$ feed concentration ratio for the reaction mechanism analyzed by steady-state conditions. The third point $\mathrm{CH}_{4} / \mathrm{O}_{2}$ feed concentration ratio determined by extreme points in Figure 4, which is the smallest $\varphi(\varphi=0.05)$, the culmination of $\varphi$ at a flow rate of methane $3.0 \mathrm{e}-4 \mathrm{~m} / \mathrm{sec}(\varphi=1)$, point average and peak flow rate of methane $\varphi$ at $10.5 \mathrm{e}-4 \mathrm{~m} / \mathrm{sec}$ and $4.5 \mathrm{e}-4$ $\mathrm{m} / \mathrm{sec}(\varphi=2.5)$. 

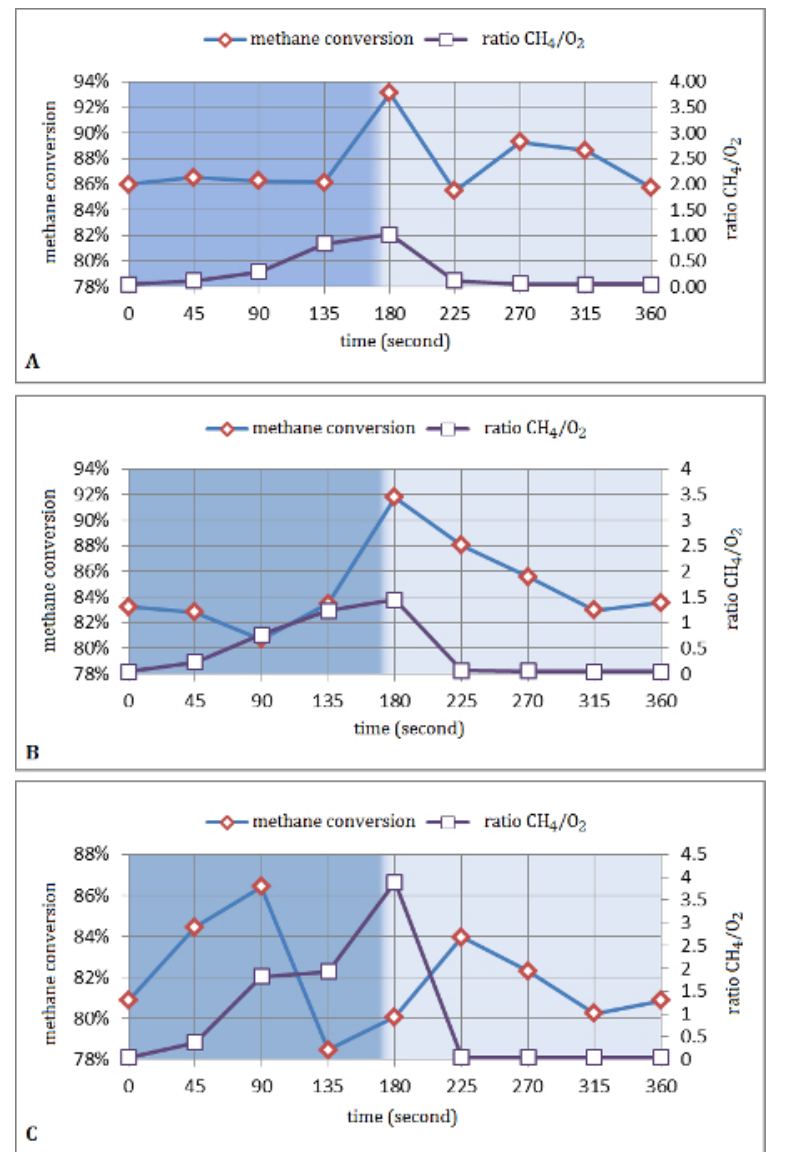

Figure 3. Behavioral response (conversion of methane) due to disturbances $\left(\mathrm{CH}_{4} / \mathrm{O}_{2}\right.$ ratio) for one full cycle at a feed flow rate of methane with methane concentration of $1 \%-\mathrm{v}$ in air. Methane flow rate of $3.0 \mathrm{e}^{-4} \mathrm{~m} / \mathrm{sec}(\mathrm{A})$; methane flow rate 4,5 $\mathrm{e}^{-4} \mathrm{~m} /$ detik (B); methane flow rate 10,5 e-4 m/second (C).

\subsection{Determine the kinetics equation of lean methane oxidation at the conditions dots feed concentration ratio $(\phi)$ results identified in step 3}

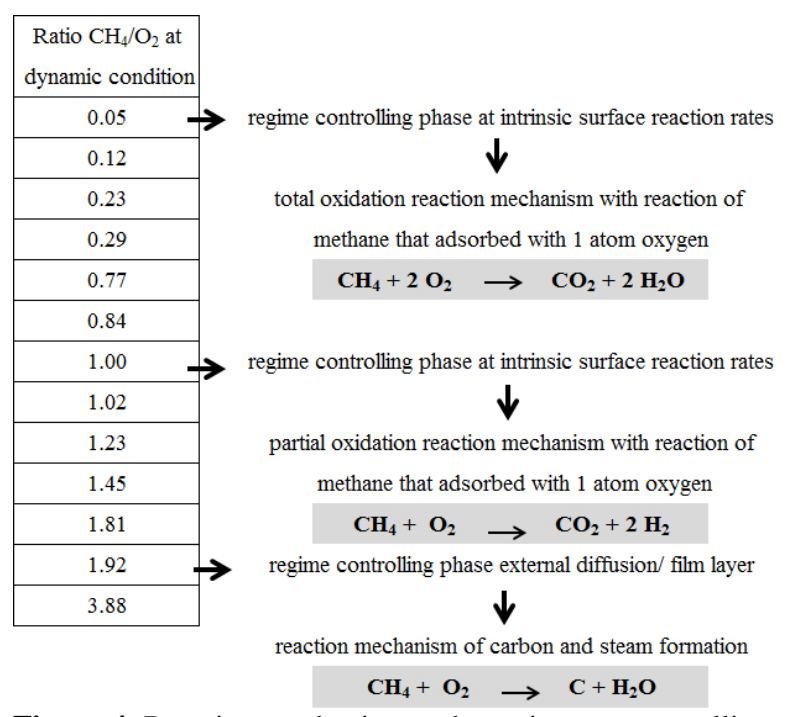

Figure 4. Reaction mechanism and reaction rate controlling step in the three-point $\mathrm{CH}_{4} / \mathrm{O}_{2}$ feed gas concentration ratio $(\varphi=0.05,1,2.5)$ are included in the dynamic range.

The identification of the reaction mechanism obtained three reaction mechanisms involved, the total oxidation of methane to $\mathrm{CO}_{2}$ and $\mathrm{H}_{2} \mathrm{O}$, the partial oxidation of methane to $\mathrm{CO}_{2}$ and $\mathrm{H}_{2}$, and the reaction of methane decomposition into $\mathrm{C}$ and $\mathrm{H}_{2} \mathrm{O}$. Table 2 shows the kinetic parameters obtained from the identification.

The patterns of transition from one mechanism to another reaction mechanism in order to get a reaction mechanism in a single cycle of dynamic conditions described at a later stage

\subsection{The develop a model of lean methane oxidation kinetics in dynamic conditions}

Determination of the transition pattern of the reaction mechanism in dynamic conditions by analyzing the reactions that occur in feed concentration ratio ranges between 0.05 and $1 \mathrm{CH}_{4} / \mathrm{O}_{2}$, ie in the range of total oxidation reaction mechanisms leading to the partial oxidation reaction mechanism. Set $\phi=0.2$ for analyzing the mechanism of the reaction that occurs in these conditions. The results obtained by using the same technique as the determination of kinetic parameters in other conditions, parameter kinetikanya not obtained. Therefore, is suspected in these conditions, there are two reaction mechanisms, that is the feed gas partial oxidation mechanism following total and some others follow the mechanism of partial oxidation.

The identification was done by using the following optimization percentage of the feed gas, partially from feed gas following oxidation reaction mechanism total and partly following the partial oxidation mechanism. Optimization techniques using FlexPDE software. The results obtained following the $51 \%$ feed gas total oxidation reaction mechanism and the rest follow the partial oxidation reaction mechanism. Figure 5 shows the equation that connects the feed concentration ratio $\mathrm{CH}_{4} / \mathrm{O}_{2}$ with the percentage number of moles of methane oxidation reaction mechanism following total and partial oxidation reaction mechanism.

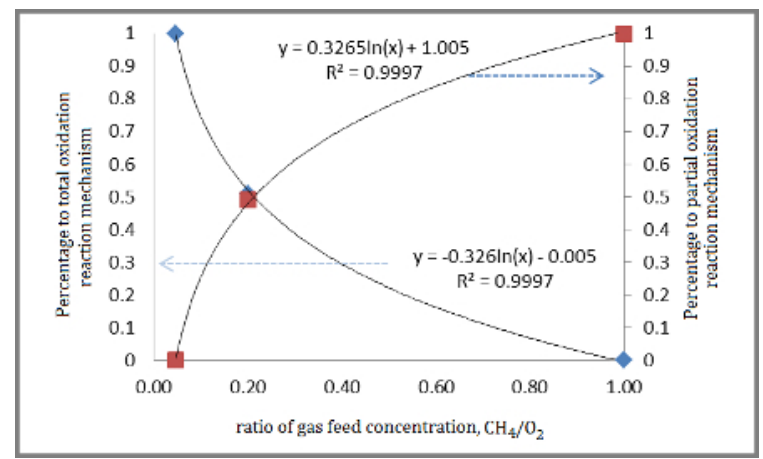

Figure 5. Equation connecting the feed concentration ratio $\mathrm{CH}_{4} / \mathrm{O}_{2}$ with the percentage number of moles of methane oxidation reaction mechanism following total and partial oxidation reaction mechanism.

From Figure 5 it can be stated, in the region 0.05 $<\varphi<1$, the percentage change in the number of moles of methane partial oxidation reaction mechanism followed a logarithmic function of with the value of the function $\mathrm{y}=$ $0.326 \ln (\varphi)+1.005$. At $\varphi>1$, significant changes, where the reaction rates are no longer being in the kinetic regime but was on the external diffusion regime as 
controlling the rate of reaction with the the reaction occurring at the surface of the catalyst is the reaction of methane decomposition into $\mathrm{C}$ and $\mathrm{H}_{2} \mathrm{O}$. At this range, $\phi$ changes that affect the acquisition methane conversion was approached by changing the value of impact factor on kinetic equations for external diffusion control stage shown in Table 2.

Overall, the transition mechanism of the reaction in one cycle of dynamic operations, which are based on changes in the concentration ratio $\mathrm{CH}_{4} / \mathrm{O}_{2}$ is caused by modulation of feedback given, as shown in Figure 6.

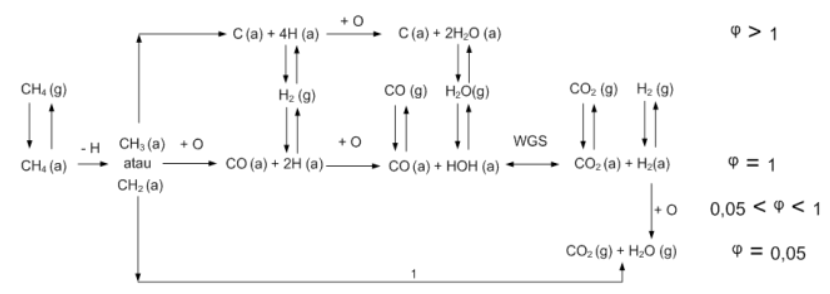

Figure 6. The transition mechanism of the reaction in one cycle of dynamic operations.

The reaction mechanism has been obtained for the dynamic conditions will be validated with the experimental results. The method is performed with the modeling and simulation. The model used to illustrate transition mechanism of the reaction in one cycle of dynamic operation is model of pseodo-homogeneous continuum 1D. Model of pseoudo-homogeneous continuum 1D with boundary conditions indicated by Equation 1-3, with the changes kinetikanya mechanisms and parameters which is a function of the concentration ratio changes $\mathrm{CH}_{4} / \mathrm{O}_{2}(\phi)$ follow the restrictions $\phi$ as follows:

$\varphi \leq 0.05$;

reaction mechanism following total oxidation of methane to $\mathrm{CO}_{2}$ and $\mathrm{H}_{2} \mathrm{O}$ with the stage control surface reaction between methane with the one atom of oxygen.

$0.05<\varphi<0.8 ; \quad$ reaction mechanisms is partially methane feed gas follow oxidation total methane into $\mathrm{CO}_{2}$ and $\mathrm{H}_{2} \mathrm{O}$ and others following the partial oxidation of methane to $\mathrm{CO}_{2}$ and $\mathrm{H}_{2}$.

$0.8<\varphi<1.1$; reaction mechanism is the following partial oxidation of methane to $\mathrm{CO}_{2}$ and $\mathrm{H}_{2}$ with the stage control surface reaction between methane with the one atom of oxygen.

$\varphi \geq 1.1 ; \quad$ reaction mechanism is followed methane decomposition reaction to $\mathrm{CO}_{2}$ and $\mathrm{H}_{2} \mathrm{O}$ with the external diffusion control stage.

Comparison of simulation results with the experimental data for various methane flow rate on methane concentration of $1 \%$-v in air is shown in Figure 7.
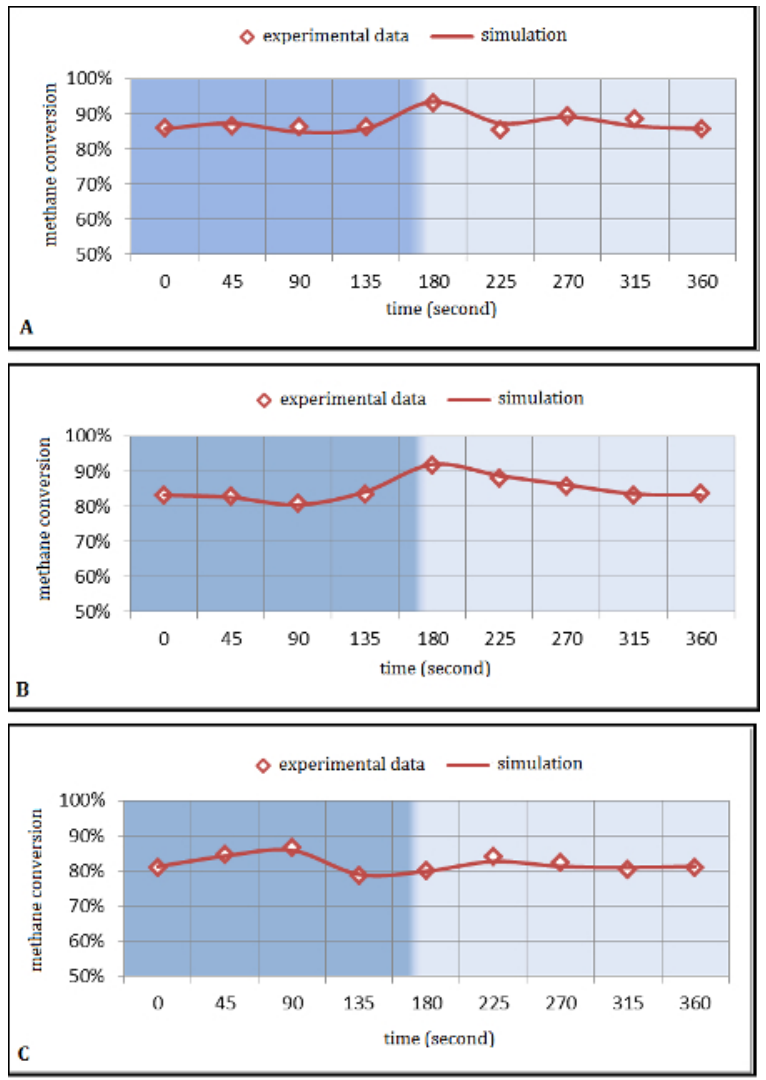

Figure 7. Comparison profile of the methane concentration at dynamic conditions between the experimental data with the the model for a linear flow rate of methane (a) $0.00030 \mathrm{~m} / \mathrm{sec}$, (b) $0.00045 \mathrm{~m} / \mathrm{sec}$, and (c) $0.00105 \mathrm{~m} / \mathrm{sec}$ at methane concentration $1 \%$-v in the air.

Figure 7 shows a model built with the attention to changes in reaction mechanisms that occur during dynamic operation in compliance. Methane conversion results obtained from simulations on dynamic conditions have values coincide with the values of methane conversion of experimental data that has noticed changes in the reaction mechanism during dynamic operation. This shows the importance of building a model of the reaction mechanism in dynamic conditions. Reaction mechanism in dynamic conditions can be approximated by the steady state reaction mechanism, with respect to kinetic regime of gas-phase reactions that might occur in porous catalysts in dynamic operation.

\section{Conclusions}

Equations should be centred and should be numbered with the number on the right-hand side.

The new method was developed to determine the mechanisms and rate controlling stage reaction that occurs in dynamic operation showed excellent results. This is indicated by the model and stage change mechanisms controlling the rate of reaction in a dynamic cycle that has been obtained to describe the characteristics of methane conversion obtained quite well, as shown in Figure 7.

Developed a new method can approximated by do segmentation the disturbance and the response to be seen reaction mechanism at steady state condition. Disorders that cause dynamic conditions in the reactor with the the 
response given by the reactor is expressed with the the ratio of the concentration of the feed gas with the methane conversion $\mathrm{CH}_{4} / \mathrm{O}_{2}$ obtained.

Reaction mechanism obtained from the segmentation of the dynamic conditions that obtain three reaction mechanisms, reaction of total oxidation of methane to $\mathrm{CO}_{2}$ and $\mathrm{H}_{2} \mathrm{O}$, the partial oxidation of methane to $\mathrm{CO}_{2}$ and $\mathrm{H} 2$, and the reaction of methane decomposition into $\mathrm{C}$ and $\mathrm{H}_{2} \mathrm{O}$, the reaction mechanisms of transition in one operating cycle of the dynamic based on changes in feed concentration due to interference ratio modulation feedback given.

\section{Nomenclature}

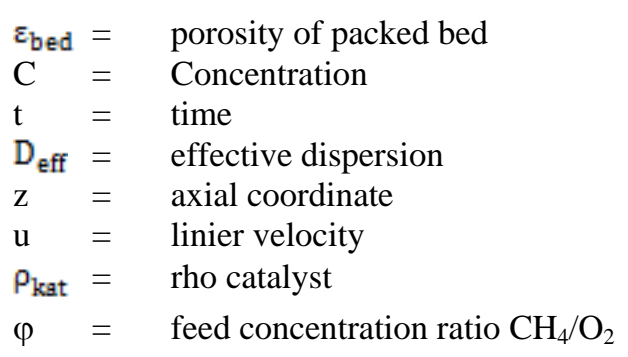

\section{References}

1. M. Cittadini, M. Vanni, A.A. Barresi, A.A. Chem. Eng. Proc. 41, 5 (2002)

2. S. Salomons, R.E. Hayes, M. Poirier, H. Sapoundjiev, Comp. Chem. Eng. 28, 9 (2004)

3. M.A.G. Hevia, S. Ordóñez, F.V. Díez. Chem. Eng. Journal, 129, 1-3 (2007)

4. P.A. Carlsson, E. Fridell, M. Skoglundh. Cat. Lett. 115, 1 (2007)

5. E. Becker, P.A. Carlsson, L. Kylhammar, M.A. Newton, M. Skoglundh, J. Phy. Chem. C, 115, 4 (2010)

6. A. Lopez, D.P. Harrison. I\&E Chem. Res. 40, 23 (2001)

7. P. Aghalayam, Y.K. Park, N. Fernandes, V. Papavassiliou, A.B. Mhadeshwar, D.G. Vlachos, J. Cat. 213, 1 (2003)

8. J. Cortes, E. Valencia, P. Araya, Cat. Lett. 112, 1 (2006)

9. P. Hurtado, S. Ordonez, H. Sastre, F.V. Diez, App. Cat. B. Environ. 51, 4 (2004)

10. S.A. Shahamiri, I. Wierzba. Chem. Eng. J, 149, 1-3 (2009)

11. S.A. Shahamiri, I. Wierzba. Iran. J. Chem. Eng. 7, 2 (2010) 